\title{
Correspondence
}

\section{Operations on the eyes of Africans}

\section{To the Editorial Committee of the British Journal of Ophthalmology}

SiRs,-Concerning the article "Failure of Filtering Operations in the African" by N. H. Welsh (British Fournal of Ophthalmology, 1970, 54, 594), I should like to bring to your attention our publication, Excision of Tenon's Capsule in Fistulizing Operation on Africans. With this technique we obtained success rates of more than 90 per cent., and it became clear that Tenon's capsule excision prevented scarring and closing of the bleb.

It should become the operation of choice in Africans. Subsequent experience in many patients and further follow-up of the group originally described confirmed our results.



\section{Book reviews}

Physiology of Colour and Pattern Vision. By K. Motokawa. 1970. Pp. 283,
I 37 figs. Igaku Shoin, Tokyo; Springer, Berlin. (DM 72; U.S. \$18.)

This book describes and discusses the long series of researches on the visual process carried out in the last 25 years by Motokawa and his co-workers in Japan. The work falls broadly into two categories: electrophysiological, including the discovery of the so-called X-component of the electroretinogram, and psychophysical, concerned mainly with the observations and implications of the effects of preexposed light stimuli on the electrical phosphene. It is this latter work - particularly with Motokawa's name - that has sometimes puzzled vision researchers in the West, and which seems to have remained separated from the main stream of development in visual science. No doubt partly responsible for this situation are two facts. Firstly, the basic initial papers appeared in the aftermath of the war, often in less easily accessible Japanese journals and, secondly, phosphene measurements of the Motokawa type involve a difficult technique and would appear to need (for success) suitable trained subjects. The present book is particularly welcome as providing an authoritative, coherent, and well-written account of the whole development, covering details of the method, the principal experimental studies, and the extensive superstructure of deduction and theory erected on the results obtained. 